\title{
Healthy life expectancy vs health expenditure by sullivan method in Malaysia
}

\author{
Muhammad Hakeem Omar, Nurin Haniah Asmuni, Sharifah Nazatul Shima \\ Faculty of Computer and Mathematical Sciences, Universiti Teknologi MARA, Malaysia
}

\begin{tabular}{l}
\hline \hline Article Info \\
\hline Article history: \\
Received Oct 12, 2018 \\
Revised Nov 30, 2018 \\
Accepted Dec 18, 2018 \\
\hline
\end{tabular}

\section{Keywords:}

Expectancy

Expenditure

Health expenditure

Healthy life expectancy

Sullivan method

\begin{abstract}
The improvement of mortality rates in many countries over the world has a major impact on cost associated with living longer due to mortality and morbidity risk. In particular, the trend in life expectancy of Malaysian population has steadily increased for many years where in 2017, Malaysian are expected to live up to 74.8 years compared to 74.3 years in 2011. Life expectancy can be defined as the average period of a person may expect to live, while the definition of disability-free life expectancy is the average number of years a person is expected to live without health disability. If a person takes a good care and services through the advancement of medical technology, it may expend the period of life expectancy for a person. Thus, longevity may have a positive relationship with health expenditure. United State for instance spends more on health across years, however United State becomes the outlier as compared to other countries with higher percentage of increase in life expectancy per dollar spent on health expenditure. Disability or disability-free life expectancy can rise at certain degree among Malaysian. The general public do not know whether longevity will expose a person to a greater period spend in disability state or not. Therefore, this paper presents healthy life expectancy vs. health expenditure by Sullivan method in Malaysia to provide further understanding of morbidity rate for Malaysian population due to longevity. This paper calculates the disability-free life expectancy for Malaysian population which then will be used in country comparison. Relationship between disability-free life expectancy and health expenditure will be studied. Sullivan method will be applied in the calculation by using a period life table based on age and gender groups.
\end{abstract}

Copyright $\left({ }_{0} 2019\right.$ Institute of Advanced Engineering and Science. All rights reserved.

\section{Corresponding Author:}

Muhammad Hakeem Omar,

Faculty of Computer and Mathematical Science,

Universiti Teknologi MARA (UiTM),

40450 Shah Alam, Selangor Darul Ehsan, Malaysia.

Email: hakeem_omar93@yahoo.com

\section{INTRODUCTION}

This paper presents healthy life expectancy vs. health expenditure by Sullivan method in Malaysia to provide further understanding of morbidity rate for Malaysian population due to longevity. This paper calculates the disability-free life expectancy of cancer patients for Malaysian population which then will be used in country comparison. The relationship between disability-free life expectancy and health expenditure will be studied.

Cancer is one of the leading cause of death categorised under 36 critical illness in Malaysia and many parts of the world. In 2007 until 2011 there are 103,507 new cases of cancer in Malaysia which is $46,794(45.2 \%)$ were males and 56,713 (54.8\%) were females. The probability of Malaysian to be diagnosed with cancer before age of 75 is one over four. In medical sector, the estimation of cancer diagnosis rate is 
crucial to plan efficiently possible treatment in ensuring optimal cost and benefit allocation of related procedure or treatment. [1]

Based on the Department of Statistics Malaysia, the mortality of population Malaysian in 2011 are expected to live up to from 74.3 years to 74.8 years in 2017 where the expected are increase by 0.5 years. The life expectancy for male is 72.7 years and 77.4 years for female. An increase in life expectancy will increase the longevity risk for a Malaysia population since there will be uncertainty of morbidity risk associated with living longer for a cancer patients. Longevity may give impact to cancer patients' survival pattern where a cancer patient may stay longer up to the current stage which is cancer patient will suffer longer than expected or they might recover from current stage and have a healthy life. With this assumption both morbidity and mortality components need to be studied further in understanding the pattern of health status of cancer patient [2][3].

Malaysia has spent RM8, 190 million in 1997 to RM49, 731 million in 2014 for total health expenditure and with the same period of range the Gross Domestic Product were from 2.91 per cent to 4.49 per cent of GDP. The per capita spending on Malaysia population health were RM642 starting in 1997 to RM1, 625 in 2014 [4].

Health status can change over the years for some causes such as the role of health-related behaviour in medical care spending, role of chronic disease and socioeconomic status where the change in economic status can affect the health investment by individual to allocate health cost. This paper aims to estimate the relationship between the healthy life expectancy and health expenditure for population in Malaysia [5][6].

This study involved population in Malaysia. The data were obtain based on the age group and gender. Data has been collected from National Cancer Institute and Malaysia National Health Accounts. Sullivan method were used in this study to calculate the number of year of person expected to live in the healthy state for a particular time. Moreover, the relationship of healthy life expectancy and health expenditure will be tested. Result in this study shows that Malaysia population life expectancy and disabilityfree life expectancy for cancer patients has increase throughout year 2007 until 2011, however the proportion comparison between life expectancy and disability-free life expectancy for Malaysia population without cancer were decrease for majority group of age throughout year 2007 until 2011, even though health expenditure spend per capita in Malaysia increase year by year.

\section{RESEARCH METHOD}

\subsection{Data Collection}

Data collection is a process to determining type of variables to help in responding the study questions and achieving the purposes. All the data were collected from National Cancer Institute and Malaysia National Health Accounts on Malaysia population based on age of group and gender throughout from year 2007 until 2011 which is 5 years duration, and form age group of five year age interval starting age of birth until 80 years old and above.

\subsection{Sullivan Method}

Sullivan's method can be used to calculate life expectancy where the life expectancy can be categories as lengths of time spent in different state of health until death. Sullivan method health expectancy can show the current health for a real population that has been adjusted for independent age structure and mortality levels. Sullivan required data of age-specific prevalence or proportions of population that were in healthy and unhealthy states. Other data are needed for calculation is age-specific mortality that are taken from a period life table. However, Sullivan method does not sensitive with size of age group, therefore an abridged life table may be used [7-8]. After the calculation of life expectancy for population, the data required the disability Healthy life expectancy is found by partitioning the persons years lived at that age into those lived with cancer or without cancer. By assuming the Cancer-free (CF) and Cancer $(C)$ then the Cancer-Free Life Expectancy at age x (CFLE) and Cancer Life Expectancy at age x (CLE) are defined by [78]:

$$
\begin{aligned}
& C F L E_{x}=\frac{1}{\ell_{x}} \sum_{i=x}^{\omega} L_{i}(C F) \\
& C L E_{x}=\frac{1}{\ell_{x}} \sum_{i=x}^{\omega} L_{i}(C)
\end{aligned}
$$

Where $L_{i}(\mathrm{CF})$ and $L_{i}(\mathrm{C})$ is defined as a number of person years lived from the age $\mathrm{x}$ onwards in the Cancerfree and Cancer respectively. Sullivan method can approximate the healthy expectancy with the hypothesis that [7-8]: 


$$
L_{i}(C)=\pi_{i} L_{i}, \text { where } \mathrm{i}=0 \text { until } \omega
$$

$\pi_{i}$ is the prevalence of person in Cancer at age $\mathrm{i}$. Thus for $\mathrm{x}=0$ until $\omega$ :

$$
\begin{aligned}
& C F L E_{x}=\frac{1}{\ell_{x}} \sum_{i=x}^{\omega}\left(1-\pi_{i}\right) L_{i} \\
& C L E_{x}=\frac{1}{\ell_{x}} \sum_{i=x}^{\omega}\left(\pi_{i}\right) L_{i}
\end{aligned}
$$

\section{RESULTS AND ANALYSIS}

\subsection{Total Life Expectancy}

Table 1 show the result that indicate male and female population life expectancy increase from year 2007 until 2011 for each group of age where population group age 80 and above has the lowest life expectancy. For life expectancy without cancer for male and female population has increase year by year where group of age from birth has the highest expectancy compare to group of age 80 years and above. Please refer appendix for further details of life expectancy and cancer-free life expectancy each year from

\begin{tabular}{|c|c|c|c|c|c|c|c|c|}
\hline \multirow[b]{3}{*}{ Age } & \multicolumn{4}{|c|}{ Male } & \multicolumn{4}{|c|}{ Female } \\
\hline & \multicolumn{2}{|c|}{2007} & \multicolumn{2}{|c|}{2011} & \multicolumn{2}{|c|}{2007} & \multicolumn{2}{|c|}{2011} \\
\hline & $\mathbf{e}_{\mathrm{x}}$ & CFLEx & $\mathbf{e}_{\mathbf{x}}$ & CFLEx & $\overline{\mathbf{e}_{\mathrm{x}}}$ & CFLEx & $\mathbf{e}_{\mathbf{x}}$ & CFLEx \\
\hline 0 & 70.180 & 70.090 & 71.970 & 71.869 & 74.750 & 74.633 & 77.050 & 76.929 \\
\hline $1-4$ & 69.610 & 69.514 & 71.340 & 71.233 & 74.110 & 73.998 & 76.370 & 76.249 \\
\hline $5-9$ & 65.730 & 65.632 & 67.420 & 67.315 & 70.210 & 70.099 & 72.450 & 72.326 \\
\hline $10-14$ & 60.820 & 60.730 & 62.490 & 62.386 & 65.300 & 65.185 & 67.510 & 67.384 \\
\hline $15-19$ & 55.940 & 55.846 & 57.580 & 57.481 & 60.380 & 60.268 & 62.570 & 62.448 \\
\hline $20-24$ & 51.230 & 51.139 & 52.870 & 52.773 & 55.500 & 55.386 & 57.670 & 57.543 \\
\hline $25-29$ & 46.590 & 46.496 & 48.190 & 48.085 & 50.630 & 50.518 & 52.790 & 52.662 \\
\hline $30-34$ & 41.990 & 41.899 & 43.500 & 43.395 & 45.780 & 45.664 & 47.920 & 47.797 \\
\hline $35-39$ & 37.500 & 37.409 & 38.870 & 38.764 & 40.960 & 40.852 & 43.060 & 42.940 \\
\hline $40-44$ & 33.040 & 32.944 & 34.300 & 34.204 & 36.200 & 36.093 & 38.250 & 38.136 \\
\hline $45-49$ & 28.610 & 28.519 & 29.810 & 29.712 & 31.520 & 31.415 & 33.520 & 33.408 \\
\hline $50-54$ & 24.310 & 24.215 & 25.480 & 25.378 & 26.980 & 26.880 & 28.900 & 28.800 \\
\hline $55-59$ & 20.170 & 20.085 & 21.380 & 21.288 & 22.560 & 22.480 & 24.440 & 24.347 \\
\hline $60-64$ & 16.320 & 16.243 & 17.490 & 17.398 & 18.390 & 18.314 & 20.180 & 20.096 \\
\hline $65-69$ & 12.930 & 12.862 & 13.940 & 13.860 & 14.540 & 14.476 & 16.220 & 16.151 \\
\hline $70-74$ & 9.900 & 9.838 & 10.710 & 10.647 & 11.110 & 11.063 & 12.510 & 12.453 \\
\hline $75-79$ & 7.480 & 7.437 & 8.110 & 8.056 & 8.180 & 8.147 & 9.380 & 9.337 \\
\hline $80+$ & 5.490 & 5.459 & 5.860 & 5.822 & 6.150 & 6.129 & 6.790 & 6.760 \\
\hline
\end{tabular}
2007 until 2011.

Table 1. Life Expectancy $\left(\mathrm{e}_{\mathrm{x}}\right)$ and Cancer-free Life Expectancy (CFLEx) in Year 2007 and 2011

\subsection{Proportion of Life Spent without Cancer}

This section shows result of proportion comparison between life expectancy and disability-free life expectancy of cancer patients. Figure 1 shows that male population has decreasing of proportion of life spent with cancer-free throughout year 2007 to 2011. However there is increasing in proportion of life spent without cancer for age 40 to 44 and 70 to 74. On the other hand, Figure 2 show for female population have the same scenario where the proportion of life spent cancer-free decrease from year 2007 until 2011 except for age 50 to 54 and 65 to 69

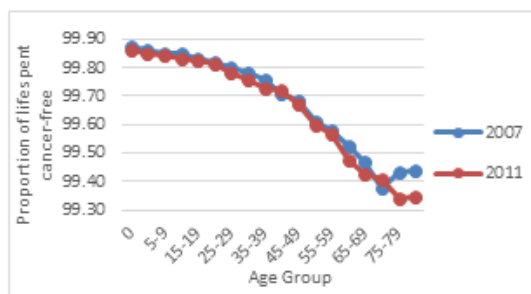

Figure 1. Comparison proportion of life spent

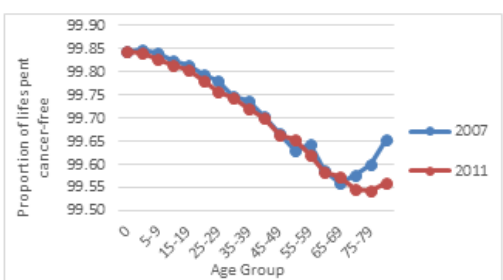

Figure 2. Comparison proportion of life spent 
without cancer for male in year 2007 and 2011

without cancer for female in year 2007 and 2011

\subsection{Health Expenditure}

Figure 3 show the spending on health per capita for Malaysia population in years 1997 to 2014. The graph show in 1997 Malaysia spend RM642 per capita and the spending increasing to RM1, 625 in years 2014. Ministry of Health Malaysia stated that they has spent RM8, 190 million for total health expenditure in year 1997 to RM49, 731 million in 2014.To follow the timeframe of this study, the spending on health per capita in 2007 was RM1, 125, in 2008 was RM1, 120, in 2009 was RM1, 268, in 2010 was RM1, 347 and 2011 was RM1, 363. The total health expenditure in Malaysia with the same period of time was RM25, 921, RM28, 843, RM31, 060, RM35, 231 and RM38, 206 respectively.

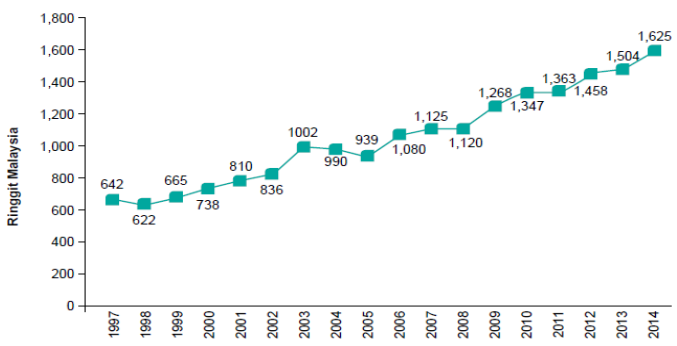

Figure 3. Graph of per capita spending on health, 1997-2014 (constant, RM) [4]

\section{CONCLUSION}

This paper presented healthy life expectancy versus health expenditure by Sullivan method in Malaysia. From the results, it show that's Malaysia population life expectancy and disability-free life expectancy has increase throughout year 2007 until 2011 which proved that Malaysia has healthy life, however the proportions comparison between life expectancy and disability-free life expectancy of cancer patients in Malaysia has decrease from year to year which lead to where Malaysian cancer patients spend more of their life in disability state. In conclusion, even though Malaysia has increase their spending on health per capita from year to year nevertheless the proportion comparison between life expectancy and disability-free life expectancy of cancer patients in Malaysia has decrease.

\section{REFERENCES}

[1] A. M. Azizah, I. T. Nor Saleha, A. Noor Hashimah, Z. A. Asmah, and W. Mastulu, "Malaysian National Cancer Registry Report 2007-2011, Malaysia Cancer Statistics, Data and Figure," Natl. Cancer Institue, vol. 16, p. 203, 2016.

[2] Department of Statistics Malaysia, "Department of Statistics Malaysia Press Release Abridged Life Tables, Malaysia , 2015-2017," 2017.

[3] S. Samsuddin and N. Ismail, "Transition probabilities of health states for workers in Malaysia using a Markov chain model," AIP Conf. Proc., vol. 1830, 2017.

[4] Ministry of Health Malaysia, "Malaysia National Health Accounts: Health Expenditure Report 1997 - 2014 ," vol. 16, 2014.

[5] S. N. Shair, A. Y. Yusof, and N. H. Asmuni, "Evaluation of the product ratio coherent model in forecasting mortality rates and life expectancy at births by States," AIP Conf. Proc., vol. 1842, 2017.

[6] S. Shair, S. Purcal, and N. Parr, "Evaluating Extensions to Coherent Mortality Forecasting Models," Risks, vol. 5, no. 1, p. 16, 2017.

[7] C. Jagger, H. Van Oyen, and J. Robine, Health Expectancy Calculation by the Sullivan Method: A Practical Guide, no. October. 2014.

[8] E. Hauet and N. Brouard, "Health Expectancy Calculation by the Sullivan Method: A Practical Guide European Concerted Action on the Harmonization of Health Expectancy Calculations in Europe (EURO-REVES)," 2001.

\section{APPENDIX}

Table 1. Proportion of Life Spent Without Cancer for Male (M) and Female (F) in Malaysia Population

\begin{tabular}{ccccccccccc} 
Age & \multicolumn{2}{c}{$\begin{array}{c}\text { Proportion of life } \\
\text { spent cancer-free }\end{array}$} & \multicolumn{2}{c}{$\begin{array}{c}\text { Proportion of life } \\
\text { spent cancer-free }\end{array}$} & \multicolumn{2}{c}{$\begin{array}{c}\text { Proportion of life } \\
\text { spent cancer-free }\end{array}$} & \multicolumn{2}{c}{$\begin{array}{c}\text { Proportion of life } \\
\text { spent cancer-free }\end{array}$} & \multicolumn{2}{c}{$\begin{array}{c}\text { Proportion of life } \\
\text { spent cancer-free }\end{array}$} \\
\hline & $\mathrm{M}$ & $\mathrm{F}$ & $\mathrm{M}$ & $\mathrm{F}$ & $\mathrm{M}$ & $\mathrm{F}$ & $\mathrm{M}$ & $\mathrm{F}$ & $\mathrm{M}$ & $\mathrm{F}$ \\
0 & 99.87 & 99.84 & 99.87 & 99.84 & 99.86 & 99.85 & 99.86 & 99.84 & 99.86 & 99.84 \\
$1-4$ & 99.86 & 99.85 & 99.86 & 99.84 & 99.86 & 99.85 & 99.85 & 99.84 & 99.85 & 99.84 \\
\hline
\end{tabular}

Healthy life expectancy VS health expenditure by sullivan method in Malaysia (Muhammad Hakeem Omar) 


\begin{tabular}{|c|c|c|c|c|c|c|c|c|c|c|}
\hline \multirow{2}{*}{$\begin{array}{c}\text { Age } \\
5-9\end{array}$} & \multicolumn{2}{|c|}{$\begin{array}{c}2007 \\
\text { Proportion of life } \\
\text { spent cancer-free }\end{array}$} & \multicolumn{2}{|c|}{$\begin{array}{l}2008 \\
\text { Proportion of life } \\
\text { spent cancer-free }\end{array}$} & \multicolumn{2}{|c|}{$\begin{array}{c}2009 \\
\text { Proportion of life } \\
\text { spent cancer-free }\end{array}$} & \multicolumn{2}{|c|}{$\begin{array}{l}2010 \\
\text { Proportion of life } \\
\text { spent cancer-free }\end{array}$} & \multicolumn{2}{|c|}{$\begin{array}{l}2011 \\
\text { Proportion of life } \\
\text { spent cancer-free }\end{array}$} \\
\hline & 99.85 & 99.84 & 99.86 & 99.84 & 99.84 & 99.84 & 99.84 & 99.83 & 99.84 & 99.83 \\
\hline $10-14$ & 99.85 & 99.82 & 99.85 & 99.83 & 99.84 & 99.81 & 99.84 & 99.81 & 99.83 & 99.81 \\
\hline $15-19$ & 99.83 & 99.81 & 99.83 & 99.80 & 99.82 & 99.80 & 99.82 & 99.80 & 99.83 & 99.81 \\
\hline $20-24$ & 99.82 & 99.80 & 99.82 & 99.79 & 99.81 & 99.79 & 99.80 & 99.78 & 99.82 & 99.78 \\
\hline $25-29$ & 99.80 & 99.78 & 99.79 & 99.77 & 99.80 & 99.76 & 99.78 & 99.78 & 99.78 & 99.76 \\
\hline $30-34$ & 99.78 & 99.75 & 99.79 & 99.75 & 99.76 & 99.75 & 99.77 & 99.75 & 99.76 & 99.74 \\
\hline $35-39$ & 99.76 & 99.74 & 99.74 & 99.72 & 99.75 & 99.72 & 99.73 & 99.71 & 99.73 & 99.72 \\
\hline $40-44$ & 99.71 & 99.70 & 99.72 & 99.71 & 99.72 & 99.69 & 99.71 & 99.71 & 99.72 & 99.70 \\
\hline $45-49$ & 99.68 & 99.67 & 99.66 & 99.66 & 99.67 & 99.66 & 99.67 & 99.67 & 99.67 & 99.67 \\
\hline $50-54$ & 99.61 & 99.63 & 99.63 & 99.66 & 99.63 & 99.63 & 99.62 & 99.66 & 99.60 & 99.65 \\
\hline $55-59$ & 99.58 & 99.65 & 99.56 & 99.64 & 99.56 & 99.63 & 99.55 & 99.61 & 99.57 & 99.62 \\
\hline $60-64$ & 99.53 & 99.59 & 99.52 & 99.61 & 99.51 & 99.59 & 99.51 & 99.59 & 99.48 & 99.58 \\
\hline $65-69$ & 99.47 & 99.56 & 99.46 & 99.58 & 99.40 & 99.58 & 99.43 & 99.59 & 99.43 & 99.57 \\
\hline $70-74$ & 99.38 & 99.58 & 99.39 & 99.59 & 99.38 & 99.55 & 99.43 & 99.61 & 99.41 & 99.55 \\
\hline $75-79$ & 99.43 & 99.60 & 99.39 & 99.63 & 99.41 & 99.61 & 99.37 & 99.61 & 99.34 & 99.54 \\
\hline $80+$ & 99.44 & 99.65 & 99.34 & 99.62 & 99.47 & 99.57 & 99.47 & 99.54 & 99.35 & 99.56 \\
\hline
\end{tabular}

Note: Number of incidence per 100,000 population.

Table 2. Life Expectancy and Cancer-free Life Expectancy for Male in Malaysia Population

\begin{tabular}{|c|c|c|c|c|c|c|c|c|c|c|}
\hline \multirow[b]{2}{*}{ Age } & \multicolumn{2}{|c|}{2007} & \multicolumn{2}{|c|}{2008} & \multicolumn{2}{|c|}{2009} & \multicolumn{2}{|c|}{2010} & \multicolumn{2}{|c|}{2011} \\
\hline & $\begin{array}{c}\text { Life } \\
\text { expectancy }\end{array}$ & $\begin{array}{c}\text { Cancer-free } \\
\text { life } \\
\text { expectancy }\end{array}$ & $\begin{array}{c}\text { Life } \\
\text { expectancy }\end{array}$ & $\begin{array}{c}\text { Cancer-free } \\
\text { life } \\
\text { expectancy }\end{array}$ & $\begin{array}{c}\text { Life } \\
\text { expectancy }\end{array}$ & $\begin{array}{c}\text { Cancer-free } \\
\text { life } \\
\text { expectancy }\end{array}$ & $\begin{array}{c}\text { Life } \\
\text { expectancy }\end{array}$ & $\begin{array}{c}\text { Cancer-free } \\
\text { life } \\
\text { expectancy }\end{array}$ & $\begin{array}{c}\text { Life } \\
\text { expectancy }\end{array}$ & $\begin{array}{c}\text { Cancer-free } \\
\text { life } \\
\text { expectancy }\end{array}$ \\
\hline 0 & 70.1800 & 70.0898 & 70.20 & 70.11 & 71.64 & 71.54 & 71.68 & 71.58 & 71.97 & 71.87 \\
\hline $1-4$ & 69.6100 & 69.5140 & 69.65 & 69.55 & 70.92 & 70.82 & 71.05 & 70.95 & 71.34 & 71.23 \\
\hline $5-9$ & 65.7300 & 65.6321 & 65.76 & 65.66 & 67.02 & 66.91 & 67.14 & 67.04 & 67.42 & 67.31 \\
\hline $10-14$ & 60.8200 & 60.7299 & 60.85 & 60.76 & 62.09 & 61.99 & 62.21 & 62.11 & 62.49 & 62.39 \\
\hline $15-19$ & 55.9400 & 55.8457 & 55.97 & 55.88 & 57.20 & 57.10 & 57.32 & 57.22 & 57.58 & 57.48 \\
\hline $20-24$ & 51.2300 & 51.1386 & 51.27 & 51.18 & 52.42 & 52.32 & 52.62 & 52.51 & 52.87 & 52.77 \\
\hline $25-29$ & 46.5900 & 46.4960 & 46.64 & 46.54 & 47.73 & 47.63 & 47.95 & 47.85 & 48.19 & 48.09 \\
\hline $30-34$ & 41.9900 & 41.8993 & 42.01 & 41.92 & 43.06 & 42.96 & 43.27 & 43.17 & 43.50 & 43.39 \\
\hline $35-39$ & 37.5000 & 37.4087 & 37.54 & 37.44 & 38.46 & 38.36 & 38.67 & 38.57 & 38.87 & 38.76 \\
\hline $40-44$ & 33.0400 & 32.9441 & 33.10 & 33.01 & 33.93 & 33.83 & 34.13 & 34.03 & 34.30 & 34.20 \\
\hline $45-49$ & 28.6100 & 28.5188 & 28.68 & 28.58 & 29.46 & 29.36 & 29.65 & 29.55 & 29.81 & 29.71 \\
\hline $50-54$ & 24.3100 & 24.2149 & 24.39 & 24.30 & 25.16 & 25.07 & 25.35 & 25.25 & 25.48 & 25.38 \\
\hline $55-59$ & 20.1700 & 20.0854 & 20.30 & 20.21 & 21.07 & 20.98 & 21.27 & 21.17 & 21.38 & 21.29 \\
\hline $60-64$ & 16.3200 & 16.2427 & 16.45 & 16.37 & 17.19 & 17.11 & 17.38 & 17.30 & 17.49 & 17.40 \\
\hline $65-69$ & 12.9300 & 12.8617 & 13.08 & 13.01 & 13.71 & 13.63 & 13.89 & 13.81 & 13.94 & 13.86 \\
\hline $70-74$ & 9.9000 & 9.8384 & 10.03 & 9.97 & 10.54 & 10.47 & 10.67 & 10.61 & 10.71 & 10.65 \\
\hline $75-79$ & 7.4800 & 7.4374 & 7.54 & 7.49 & 8.06 & 8.01 & 8.14 & 8.09 & 8.11 & 8.06 \\
\hline $80+$ & 5.4900 & 5.4592 & 5.53 & 5.49 & 5.78 & 5.75 & 5.83 & 5.80 & 5.86 & 5.82 \\
\hline
\end{tabular}

Note: Number of incidence per 100,000 population.

Table 3. Life Expectancy and Cancer-free Life Expectancy for Female in Malaysia Population

\begin{tabular}{|c|c|c|c|c|c|c|c|c|c|c|}
\hline \multirow[b]{2}{*}{ Age } & \multicolumn{2}{|c|}{2007} & \multicolumn{2}{|c|}{2008} & \multicolumn{2}{|c|}{2009} & \multicolumn{2}{|c|}{2010} & \multicolumn{2}{|c|}{2011} \\
\hline & $\begin{array}{c}\text { Life } \\
\text { expectancy }\end{array}$ & $\begin{array}{l}\text { Cancer- } \\
\text { free life } \\
\text { expectancy }\end{array}$ & $\begin{array}{c}\text { Life } \\
\text { expectancy }\end{array}$ & $\begin{array}{l}\text { Cancer- } \\
\text { free life } \\
\text { expectancy }\end{array}$ & $\begin{array}{c}\text { Life } \\
\text { expectancy }\end{array}$ & $\begin{array}{l}\text { Cancer- } \\
\text { free life } \\
\text { expectancy }\end{array}$ & $\begin{array}{c}\text { Life } \\
\text { expectancy }\end{array}$ & $\begin{array}{l}\text { Cancer- } \\
\text { free life } \\
\text { expectancy }\end{array}$ & $\begin{array}{c}\text { Life } \\
\text { expectancy }\end{array}$ & $\begin{array}{l}\text { Cancer- } \\
\text { free life } \\
\text { expectancy }\end{array}$ \\
\hline $1-4$ & 74.1100 & 73.9983 & 74.17 & 74.05 & 75.80 & 75.68 & 76.10 & 75.98 & 76.37 & 76.25 \\
\hline $5-9$ & 70.2100 & 70.0985 & 70.27 & 70.16 & 71.89 & 71.77 & 72.19 & 72.06 & 72.45 & 72.33 \\
\hline $10-14$ & 65.3000 & 65.1853 & 65.34 & 65.23 & 66.96 & 66.83 & 67.25 & 67.12 & 67.51 & 67.38 \\
\hline $25-29$ & 50.6300 & 50.5182 & 50.67 & 50.55 & 52.26 & 52.14 & 52.54 & 52.42 & 52.79 & 52.66 \\
\hline $30-34$ & 45.7800 & 45.6643 & 45.82 & 45.71 & 47.39 & 47.27 & 47.68 & 47.56 & 47.92 & 47.80 \\
\hline $35-39$ & 40.9600 & 40.8520 & 41.01 & 40.89 & 42.55 & 42.43 & 42.84 & 42.72 & 43.06 & 42.94 \\
\hline $40-44$ & 36.2000 & 36.0929 & 36.25 & 36.14 & 37.75 & 37.63 & 38.03 & 37.92 & 38.25 & 38.14 \\
\hline $45-49$ & 31.5200 & 31.4151 & 31.57 & 31.46 & 33.03 & 32.92 & 33.31 & 33.20 & 33.52 & 33.41 \\
\hline $70-74$ & 11.1100 & 11.0630 & 11.18 & 11.13 & 12.17 & 12.12 & 12.40 & 12.35 & 12.51 & 12.45 \\
\hline $75-79$ & 8.1800 & 8.1473 & 8.29 & 8.26 & 9.11 & 9.07 & 9.31 & 9.27 & 9.38 & 9.34 \\
\hline $80+$ & 6.1500 & 6.1288 & 6.19 & 6.17 & 6.64 & 6.61 & 6.74 & 6.71 & 6.79 & 6.76 \\
\hline
\end{tabular}

Note: Number of incidence per 100,000 population. 